\title{
REPRESENTAÇÕES DOS NEGROS NOS LIVROS DIDÁTICOS DE HISTÓRIA DO ESPÍRITO SANTO (1964-1997)
}

\section{REPRESENTATION OF THE BLACKS IN THE DIDATIC BOOKS OF HISTORY IN THE ESPIRITO SANTO (1964-1997)}

\author{
Leonardo Nascimento Bourguignon \\ Professor da rede estadual de ensino do estado do Goiás, Brasil \\ Mestre em educação pela Universidade Federal do Espírito Santo, Brasil \\ e-mail: leo.alice.marina@gmail.com
}

DOI:

http://dx.doi.org/10.26512/hh.v5i9.10985

Recebido em 11 de novembro de 2016

Aprovado em 24 de maio de 2017

\section{RESUMO}

Neste artigo analisaremos o papel do livro didático enquanto instrumento de propagação e consolidação de representações, mais especificamente das representações acerca do negro nos livros de história regional. Com esse propósito, após apresentarmos a permanência de uma tendência preconceituosa e estereotipada nos livros didáticos brasileiros nos séculos XIX e XX, optamos por verificar se essas mesmas tendências foram reiteradas nos livros escolares de história do Espírito Santo publicados no período de 1964 até 1997. Com o desenvolvimento da pesquisa, constatamos que, apesar da permanência de uma escrita eurocêntrica, os livros produzidos por autores capixabas apresentaram, em diversos momentos, o negro como agente ativo na história local, mesmo antes da existência de uma legislação que assim os exigisse, e a frente inclusive de uma tendência nacional.

Palavras-chave: negros; representações; livros didáticos; história regional; Espírito Santo.

\begin{abstract}
In this article we will concentrate on Textbook as an instrument of spreading and consolidating representations, specifically the representations of black in regional history books. With this purpose, after presenting the permanence of a biased and stereotyped tendency in the Brazilian textbooks in the 19th and 20th centuries, we chose to verify if these same trends were reiterated in the Espírito Santo history textbooks published between 1964 and 1997. With the development of the research, we find that, despite the permanence of a Eurocentric writing, the books produced by Capixabas authors presented at various moments the Negro as an active agent in local history, even before the existence of legislation that required them, and even front of a national trend.
\end{abstract}

Keywords: black people; representations; textbooks; regional history; Espírito Santo

“amalgamação muito difícil será a liga de tanto metal heterogêneo, como brancos, mulatos, pretos livres e escravos, índios etc. em um corpo sólido político". ${ }^{1}$

\footnotetext{
${ }^{1}$ ANDRADA E SILVA, José Bonifácio de. Projetos para o Brasil (organização de Miriam Dolhnikoff). São Paulo: Companhia das Letras, 1998, p. 170.
} 
À constatação de José Bonifácio de Andrada e Silva, os fundadores da História do Brasil e de seu ensino, diante do compromisso de forjar uma identidade nacional, construíram no século XIX uma narrativa que privilegiava a ancestralidade portuguesa. Naquela concepção foram os lusos os responsáveis pela manutenção e integração entre as distintas, e distantes, províncias que formavam o imenso país. Conseguiram ainda, afastar os inimigos da unidade nacional que nas narrativas eram os outros povos europeus, os quilombolas ou os povos indígenas.

Por vezes, a postura diante das diversas etnias, homogeneizadas e pejorativamente denominadas índios e negros, alterou-se para a evocação de aspectos pitorescos e folclóricos de suas culturas objetivando promover uma identificação e valorização nacional. ${ }^{2}$ Nesse sentido, apesar da intensa valorização dos imigrantes europeus na constituição do povo capixaba, foram a panela de barro e o congo, elementos das culturas indígena e negra, os objetos adotados como símbolos do estado do Espírito Santo.

Outra atitude foi a homenagem a índios e negros que de alguma forma contribuíram para o processo colonizador português, como podemos perceber no movimento indianista, no qual o índio tomado como modelo da nacionalidade era o que pertencera ao tronco tupi. Sujeitos como Filipe Camarão, eleito herói por Francisco Adolfo de Varnhagen devido a seus préstimos nos conflitos contra os holandeses e os povos indígenas locais que ficaram do lado desses e outros “invasores".

Mesmo com o advento do século XX, a instalação de um novo regime político e a ascensão de autores como João Ribeiro e Capistrano de Abreu que inauguraram uma nova fase da historiografia nacional visibilizando novos atores sociais na construção do país, a representação de índios e negros na história escolar e acadêmica continuou inferiorizada, afinal as representações "são sempre determinadas pelos interesses dos grupos que as forjam". ${ }^{3}$ Desta forma, mesmo na história renovada de Capistrano de Abreu e João Ribeiro; que apontavam que "nas suas feições e fisionomia própria, o Brasil [...] deriva do colono, do jesuíta e do mameluco, da ação dos índios e dos escravos negros"; ; uma suposta hierarquia entre as raças, jamais foi negada.

Abordando a década de 1930, Schwartz concluiu que o predomínio do marxismo sobre o pensamento historiográfico brasileiro, que duraria até 1970, trouxe para o palco das

\footnotetext{
${ }^{2}$ WEHLING, Arno. Estado, História, Memória: Varnhagen e a construção da identidade nacional. Rio de Janeiro: Nova Fronteira, 1999.

${ }^{3}$ CHARTIER, Roger. A história cultural entre práticas e representações. Lisboa: Difel, 1990, p. 17.

${ }^{4}$ RIBEIRO, João. História do Brasil. Curso Superior. 9 ed. Rio de Janeiro: Francisco Alves, 1920, p. 17.
} 
discussões nacionais problemas como classe e raça. ${ }^{5}$ Desta forma, trabalhos publicados na década de 1950 como A pesquisa de estereótipos e valores nos compêndios de História destinados ao curso secundário brasileiro, de Guy Holanda (1957); Preconceito racial e patriotismo em seis livros didáticos primários, de Dante Moreira Leite (1950); Valores e estereótipos em livros de leitura, de Bazzanella (1957) e o texto de Guiomar Ferreira de Mattos, O preconceito nos livros infantis (1954) somados aos protestos das associações negras, denunciaram que os livros escolares apresentavam, de forma geral,

personagens negros em situação social inferior; superioridade da raça branca em beleza e inteligência; postura de desprezo e/ou piedade em relação ao negro [...] figura do negro estava associada a funções subalternas, escravidão [...] justificada como uma necessidade econômica. ${ }^{6}$

$\mathrm{Na}$ década de 1970, apesar das tentativas de cerceamento do regime militar, o movimento de revisionismo, que marcou boa parte da produção historiográfica acadêmica do período, alcançou a historiografia sobre o negro no Brasil, desdobrando-se posteriormente nos livros didáticos. ${ }^{7}$ Essa renovação historiográfica, segundo Schwartz provocada pelo advento em terras brasileiras da História Social e da História Econômica, aumentou a produção de estudos que enfatizavam a resistência e a rebeldia dos escravizados. $^{8}$

No campo das pesquisas sobre livros didáticos, trabalhos como o de Circe Bittencourt demonstraram que até a década de 1980 houve poucos estudos sobre esses objetos. ${ }^{9}$ A renovação teórico-metodológica na produção historiográfica, o aumento dos cursos de pós-graduação em todo o país e a implantação do Programa Nacional do Livro Didático (PNLD) alteraram esse cenário, iniciando um movimento crescente na produção acadêmica acerca destes suportes pedagógicos. A partir de então, os livros escolares

\footnotetext{
${ }^{5}$ SCHWARTZ, Stuart. A historiografia dos primeiros tempos do Brasil Moderno. Tendências e desafios das duas últimas décadas. História: Questões e Debates, n. 50, p. 175-216, 2009.

${ }^{6}$ ROSEMBERG, Fúlvia; BAZILLI, Chirley; SILVA, Paulo Vinícius Baptista da. Racismo em livros didáticos brasileiros e seu combate: uma revisão da literatura. Educação e Pesquisa, v. 29, n. 01, p. 134, 2003. Disponível em: <http://www.scielo.br/scielo.php?script=sci_arttext\&pid=S151797022003000100010>. Acesso em: 08/11/2013.

7 OLIVEIRA, Almir Félix Batista de. A experiência do negro na historiografia didática brasileira (1840/2010). In: ENCONTRO NACIONAL DOS PESQUISADORES DO ENSINO DE HISTÓRIA: América Latina em perspectiva: culturas, memórias e saberes, IX, 2011, Florianópolis. Anais Eletrônicos... Florianópolis: s.e., 2011, p. 02. CD-ROM.

${ }^{8}$ SCHWARTZ, 2009.

9 BITTENCOURT, Circe Maria Fernandes. Produção didática de História: trajetórias de pesquisas. Revista de História, São Paulo, n. 164, p. 487-516, 2011.
} 
passaram a ser apontados como fonte histórica privilegiada para recuperação de parte da cultura escolar, objeto mercadológico e/ou instrumento de propagação e consolidação de representações. No entanto, apesar dessa ampliação, o estudo de Fúlvia Rosemberg, Chirley Bazilli e Paulo Vinícius Baptista da Silva ao analisar 114 pesquisas sobre livros didáticos publicados no Brasil, entre 1981 e 1998 sobre livros, constatou que apenas 04 referiam-se exclusivamente a questão do racismo nos livros escolares. ${ }^{10}$

Também analisando pesquisas sobre racismo em livros didáticos Esmeralda Negrão identificou nos estudos produzidos até a década de 1980 uma prevalência em denunciar preconceitos, estereótipos e discriminações explícitos e implícitos, concluindo que:

\begin{abstract}
embora uma nova concepção da relação adulto/criança, que se estabelece com a literatura, esteja surgindo, a imagem de criança compondo o público desta produção ainda apresenta o traço cor branca. [...] a discriminação racial não está presente somente no escamoteamento da história do povo negro, mas se faz presente na própria definição deste gênero de literatura, na medida em que o cotidiano e a experiência da criança negra estão alijados do ato de criação dos personagens e do enredo desta literatura. ${ }^{11}$
\end{abstract}

Vinte e três anos após a publicação daquele artigo, Oliveira concluiria que, apesar dos avanços dos últimos tempos, a historiografia didática continua "equivocada e omissa em relação à experiência negra brasileira". ${ }^{12}$ E no caso da historiografia didática regional apresentada como um rincão marcado por permanências, tradições e heranças, veiculando uma narrativa factual, enfatizando nomes e personalidades e apresentando um passado idealizado repleto de passagens romantizadas ${ }^{13}$ Que representações acerca dos negros localizaríamos nos livros escolares de história regional?

Objetivando contribuir para essa discussão optamos pelo estudo de um exemplo: a história escolar capixaba publicada entre os anos de 1964 a 1997. Recorte temporal escolhido em função de acreditarmos ser Brasil: edição especial para o Espirito Santo $(1964)^{14} \mathrm{O}$ primeiro livro didático lançado no Espírito Santo como parte de um modelo editorial que abordava na mesma obra a história regional e a história do Brasil, e que perdurou por mais

\footnotetext{
${ }^{10}$ ROSEMBER;, BAZILLI; SILVA, 2003.

11 NEGRÃO, Esmeralda V. Preconceitos e discriminações raciais em livros didáticos. Cadernos de Pesquisa, São Paulo, n. 65, p. 60, 1988.

12 OLIVEIRA, 2011, p. 06.

${ }^{13}$ PESAVENTO, Sandra Jatahy. História Regional e Transformação Social. In: SILVA, Marcos Antônio da. República em migalhas. São Paulo: Marco Zero, 1990.

${ }^{14}$ MORAES, João Barbosa de. Brasil: edição especial para o Espírito Santo. São Paulo: Editora Brasil. 1964.
} 
de duas décadas no mercado editorial capixaba. O outro limite é 1997, ano de lançamento de Nossa História, Nossa Gente, de Lea Brígida Rocha Alvarenga Rosa, Luiz Guilherme Santos Neves e Renato José da Costa Pacheco, obra que consolidou importantes alterações na escrita didática capixaba acerca do negro iniciadas pelos autores capixabas ainda na década de 1970.

Além dessas obras, neste artigo analisaremos: O Espírito Santo é Assim, ${ }^{15}$ Espirito Santo, esta é a sua terra no Brasil, ${ }^{16}$ Geografia e História do Espírito Santo - Area de Estudos Sociais, ${ }^{17}$ e Estado do Espirito Santo: estudos sociais, ${ }^{18}$ Gente, terra verde, céu azul - Estudos Sociais, ${ }^{19}$ Espírito Santo, Minha terra, minha gente ${ }^{20}$ e Meu Estado - Espirito Santo. ${ }^{21}$

\section{MESMO CONTEXTO, DIFERENTES REPRESENTAÇÕES}

Após localizar 10.887 fontes em 52 acervos, André Luiz Pirola, produziu o mais importante estudo sobre o livro didático de história no Espírito Santo publicado até o momento. ${ }^{22}$ Conforme aquele pesquisador, na década de 1970 a história escolar capixaba passou por uma série de transformações. ${ }^{23}$ Além das mudanças de ordem material, como a passagem de um modelo de confecção artesanal para uma produção industrial, a narrativa escolar naquele período consolidou uma representação de um presente desenvolvimentista em contraste a um passado de atraso, simbolizado, entre outros, no mito da "barreira verde". A hipótese professava que, diante da descoberta de ouro no interior da então Capitania do Espírito Santo no final do século XVII, a Coroa portuguesa, pretendendo conter o contrabando, criou uma nova capitania na região - a Capitania das Minas Gerais - e transformou o território capixaba, devido a sua localização geográfica, em uma barreira natural. Para isso, proibiu a abertura de estradas para o interior e construiu ou reaparelhou

${ }^{15}$ MORAES, Neida Lúcia de. O Espírito Santo é assim. s.e..: Rio de Janeiro, 1971.

${ }^{16}$ MORAES, Neida Lúcia de. Espírito Santo, esta é a sua terra no Brasil. Lisa: São Paulo, 1973.

${ }^{17}$ KILL, Miguel Arcanjo. Geografia e História do Espírito Santo. Vitória: s/ ed., 1974.

${ }^{18}$ KILL, Miguel Arcanjo. Estado do Espírito Santo: estudos sociais. 5 ed. São Paulo: Saraiva, 1983.

${ }^{19}$ MORAES, Lídia Maria; AROEIRA, Maria Luiza C.; CALDEIRA, Maria José. Gente, terra verde, céu azul. Estudos Sociais - Espírito Santo. São Paulo: Ática, 1981.

${ }^{20}$ NEVES, Luiz Guilherme Santos; PACHECO, Renato José da Costa; ROSA, Lea Brígida Rocha Alvarenga. Espírito Santo: minha terra, minha gente. História regional para o $1^{\circ}$ grau das escolas estaduais. Vitória: SEDU, 1986.

${ }^{21}$ BECHEPECHE, Morgana; ORDOÑEZ, Marlene; SALES, Geraldo. Coleção Meu Estado - Espírito Santo. São Paulo: Scipione, 1997.

${ }^{22}$ PIROLA, André Luiz B. O livro didático no Espírito Santo e o Espírito Santo no livro didático: história e representações. 265 f. Dissertação (Mestrado em Educação) - Programa de Pós Graduação em Educação, Universidade Federal do Espírito Santo, Vitória, 2008.

${ }^{23}$ PIROLA, 2008, p. 202. 
fortes no litoral. As medidas, ainda conforme aquela representação, lançaram a região no mais profundo isolamento e consequente pobreza. Apesar de estudos recentes apresentarem dados que desautorizam essa interpretação, ${ }^{24}$ ela continua sendo reafirmada mesmo nos livros mais recentes. ${ }^{25}$

A permanência desse e outros "temas, objetos, sujeitos e abordagens" nos manuais escolares, apesar da renovação da historiografia nas últimas décadas, pode ser compreendida pelo fato de que:

As diferentes gerações de intelectuais que escreveram a História do Espírito Santo, sendo aqui percebidas superpostas em uma mesma temporalidade, embora em diferentes tempos cronológicos, criavam para si identidades. Estas eram consolidadas através de uma escrita da História também com finalidade didática, e não se anulavam ao se sucederem, mas se adicionavam e se superpunham (...) [assim] as representações identitárias presentes nos atuais livros didáticos de História Regional do Espírito Santo, são também representações particulares do tempo histórico, sínteses de debates anteriores produzidas em um contexto específico, mas que são interpretações e ideias acerca de um Espírito Santo e dos espírito-santenses. ${ }^{26}$

Entre esses intelectuais que escreveram a história do Espírito Santo na segunda metade do século XX encontramos Neida Lúcia de Moraes e sua obra O Espírito Santo é Assim (1971). Apesar de não tratar-se especificamente de um livro didático, nos apropriamos da assertiva de Pirola de que não é possível compreendermos o Espírito Santo representado no livro didático a partir da década de 1970, sem tomarmos conhecimento desta obra. ${ }^{27}$ Nos últimos meses da gestão de Christiano Dias Lopes (1967-1971), o governo estadual, pretendendo consolidar no plano literário e histórico a representação desenvolvimentista forjada durante aquele governo, publicou oficialmente O Espírito Santo é Assim. ${ }^{28}$ No que tange a questão do negro, ao apresentar a Insurreição de Queimado, evento apontado pela historiografia capixaba como a maior revolta escrava ocorrida no

\footnotetext{
${ }^{24}$ Entre esses estudos destacamos: BARROS, Nicélio; RIBEIRO, Luiz Cláudio; PROTTI, David. A serventia da casa: a Alfândega do Porto de Vitória e os rumos do Espírito Santo. Vitória: Sindiex, 2008; VITÓRIA SOBRINHO, Sueni. A Economia do Estanco e o Mercado Interno na Capitania do Espírito Santo. Revista FACEVV, Vila Velha, v. 6, p. 111-130, 2011.

${ }^{25}$ HEES, Regina; FRANCO, Sebastião Pimentel. História do Espírito Santo. São Paulo: Scipione, 2012, p. 57.

${ }^{26}$ LEITE, Juçara Luzia. Práticas de leitura e escritas de si: livro didático regional e identidade geracional. In: OLIVEIRA, Margarida Maria Dias de; STAMATTO, Maria Inês Sucupira. O livro didático de História: políticas educacionais, pesquisas e ensino. Natal: EDUFRN, 2007, p. 196.

${ }^{27}$ PIROLA, 2008, p. 130-131.

${ }^{28}$ PIROLA, 2008, p. 130-131
} 
Espírito Santo, a autora utilizou o mesmo tom romântico que marcaria toda a obra, como podemos conferir no excerto a seguir:

Do ponto de vista militar, não foi mais que um motim realizado por algumas dezenas de escravos e esmagado, em dois dias, por um pelotão de soldados. Mas, do ponto de vista histórico, deve ser considerada mesmo uma insurreição pelo sentido de coragem na persecução do ideal de liberdade de uma raça à qual se negara tudo à qual se atribuía plena incapacidade para os sentimentos mais elevados. (...) O levante de Queimado é um documento de heroísmo e de altivez de uma raça caída na mais desgraçada condição e que, do fundo do abismo a que fora atirada gritava bem alto a nobreza que se the escondia na alma. ${ }^{29}$

Em 1973, Neida Lúcia promove adaptações em O Espirito Santo é Assim (1971) transformando-o no livro didático, Espírito Santo, esta é a sua terra no Brasil $3^{30}$. As semelhanças entre as duas obras levaram Pirola a concluir que "se trata de um texto único", 31 e é nesse sentido que a Insurreição de Queimado é retratada, da mesma forma que na obra anterior, como "heroica explosão da ânsia pela liberdade". ${ }^{32}$

$\mathrm{Na}$ narrativa de Neida Lúcia nos deparamos com “[...] um estado pintado com cores fortes, em alguns casos, romântico e quixotesco, que, não obstante aponta para um futuro desenvolvimentista". ${ }^{33}$ É esse estado em Marcha para o desenvolvimento que também localizamos nas obras Geografia e História do Espirito Santo - Área de Estudos Sociais (1974) e Estado do Espirito Santo: estudos sociais (1983), ambos de Miguel Arcanjo Kill, prolífico autor capixaba com livros didáticos de história regional publicados durante três décadas.

Em Geografia e História do Espírito Santo, Kill acrescentou à clássica ideia da barreira verde outros entraves à colonização/civilização do território capixaba, como os índios, as doenças e a natureza selvagem. E, diante daqueles desafios, apresentou os sujeitos históricos que "abrindo caminhos e clareiras nas matas, tornar-se-iam os maiores povoadores do interior do Estado": os imigrantes europeus. ${ }^{34}$ Nesta perspectiva, de um Espírito Santo, fruto dos esforços do imigrante europeu, o papel do negro estava claramente delineado e expresso no título da única seção em que o autor tratava especificamente dos africanos e seus descendentes: $A$ contribuição dos escravos. ${ }^{35} \mathrm{Em}$ outro de

\footnotetext{
${ }^{29}$ MORAES, 1971, p. 40

${ }^{30}$ MORAES, 1973.

${ }^{31}$ PIROLA, 2008, p. 154.

${ }^{32}$ MORAES, 1973, p. 24.

${ }^{33}$ MORAES, 1973, p. 188.

${ }^{34}$ KILL, 1974, p. 57.

${ }^{35}$ KILL, 1974.
} 
seus livros, Estado do Espirito Santo (1983), Miguel Kill renomeia a seção como $A$ boa ajuda dos escravos. ${ }^{36} \mathrm{O}$ negro então era o auxiliar do projeto colonizador europeu, iniciado pelos portugueses nos séculos XVI, XVII e XVIII e efetivado pelos imigrantes que desembarcaram no Espírito Santo na segunda metade do século XIX.

Neste sentido, as duas obras de Kill, assim como a maior parte dos livros escolares de Estudos Sociais daquele período, ao abordarem a contribuição dos africanos na formação econômica, étnica e cultural do Espírito Santo, apresentam-na como complemento à empreitada europeia. Submissão reafirmada nas ilustrações em que aparecem negros, todas elas relacionadas à escravidão. No mesmo sentido, a abolição é retratada como ação exclusiva da Princesa Isabel, ${ }^{37}$ e que envolveu "todos os intelectuais capixabas". 38

Mas, enquanto narrativa histórica, portanto portadora de múltiplas temporalidades, inclusive as mais recentes, em Geografia e História do Espirito Santo, Kill, assim como Neida Lúcia de Moraes, relatava aos estudantes capixabas que: "Houve também no Espírito Santo, a exemplo de outros estados, muitas revoltas de escravos contra seus senhores. A mais famosa delas foi a ocorrida no município da Serra, sob a denominação de Insurreição de Queimado". ${ }^{39}$ Se a inserção de revoltas escravas representou um fato inusitado nos livros escolares publicados na década de $1970,{ }^{40}$ o mesmo não pode ser afirmado no campo acadêmico. Neste, uma intensa revisão historiográfica impulsionava um aumento nas pesquisas sobre o negro na história do Brasil, especialmente de estudos relacionados a revoltas e outras formas de resistência dos escravizados. ${ }^{41}$ No estado do Espírito Santo, a federalização da Universidade Estadual no início da década de 1960 possibilitou que parte da geração de intelectuais da década de 70 e 80 do século XX, uma vez especializada, superasse parte das "representações identitárias sobre as quais se fundaram as gerações anteriores". ${ }^{42}$

\footnotetext{
${ }^{36}$ KILL, 1983

${ }^{37}$ KILL, 1974.

${ }^{38}$ MORAES, 1971, p. 42.

${ }^{39}$ KILL, 1974, p. 65.

${ }^{40}$ CONCEIÇÃO, M. T. A escrita didática da história do negro no Brasil na segunda metade do século XX: Um olhar sobre a temática na década de 1970. In: SIMPÓSIO NACIONAL DE HISTÓRIA, XXVI, 2011, São Paulo. Anais do XXVI ... São Paulo: ANPUH, 2011; ROSEMBERG; BAZILLI; SILVA, 2003.

${ }^{41}$ OLIVEIRA, 2011; SCHWARTZ, 2009.

${ }^{42}$ LEITE, Juçara Luzia. Práticas de leitura e escritas de si: livro didático regional e identidade geracional. In: OLIVEIRA, Margarida Maria Dias de; STAMATTO, Maria Inês Sucupira. O livro didático de História: políticas educacionais, pesquisas e ensino. Natal: EDUFRN, 2007. p. 194.
} 
Inseridos naquele contexto acadêmico, Miguel Kill e Neida Lúcia de Moraes introduziram em seus livros didáticos parte do que era discutido na academia e reivindicado pelo movimento negro que, como demonstra o trabalho de Petrônio Domingues, desde a década de 1930 sempre conseguiu uma importante capacidade de mobilização em território capixaba. ${ }^{43}$ Ao abordar a revolta escrava ocorrida na localidade de São José do Queimado, em 1849, Kill, apesar de reproduzir conceitos pejorativos como a ênfase na breve duração e a "desorganização dos revoltosos", ${ }^{44}$ inseriu o tema reafirmando uma representação do negro enquanto sujeito ativo e contestador. Confirmando, pois, a inserção da Revolta de Queimado nos livros escolares de história do Espírito Santo fora obra de Neida Lúcia de Moraes e, a partir de então, reiterada pelas gerações de intelectuais que produziram e compartilharam uma escrita do Espírito Santo e dos espírito-santenses.

Situação distinta foi a que apreendemos nos livros escolares Brasil: edição especial para o Espirito Santo (1964) do professor autor João Barbosa de Moraes destinada para o $3^{\circ}$ ano do antigo ensino primário; Gente, terra verde, céu azul - Estudos Sociais (1981) ${ }^{45}$ de autoria de Maria de Moraes, Maria Luísa Aroeira e Maria José Caldeira e Meu Estado: Estudos Sociais Espirito Santo (1997), de Morgana Bechepeche, Marlene Ordoñez e Geraldo Sales, obras que, apesar da distância temporal, suportam muitas características comuns. Partes de coleções nacionais, ${ }^{46}$ nos três manuais as raras referências aos africanos e seus descendentes restringiram-se à três aspectos: escravidão, Abolição e contribuições culturais. No caso da escravidão, não encontramos nas três obras uma citação sequer sobre esse tema dentro da história do Espírito Santo, levando à falsa ideia de que a mesma não ocorreu nesse Estado. Ao tratarem da Abolição, Moraes, Aroeira e Caldeira a reduziram a uma ação exclusiva da Princesa Isabel ${ }^{47}$ a quem João Barbosa de Moraes acrescentaria outras "pessoas bondosas [que] passaram a se interessar pelos sofrimentos dos escravos negros e desejavam acabar

43 DOMINGUES, Petrônio. Movimento negro brasileiro: alguns apontamentos históricos. Tempo. [online], Niterói, v. 12, n. 23, p. 104, 2007. Disponível em: <http://www.scielo.br/scielo.php?pid=S1413$77042007000200007 \&$ script=sci_abstract\&tlng=pt>. Acesso em: 05/05/2015.

44 KILL, 1974, p. 65; KILL, 1983, p. 44.

${ }^{45}$ Pirola estima que a primeira edição foi publicada em 1980, mas o único exemplar localizado em sua pesquisa foi a $3^{\text {a }}$ edição de 1981. PIROLA, 2008, p. 205.

${ }^{46}$ Denominamos nacionais as coleções publicadas por uma editora que em seus livros abordavam a história do Brasil e a do estado em que determinada obra fora publicada. É o caso da Coleção Nosso Brasil, lançada pela Bloch Editores em 1976 que era dirigida por Arnaldo Niskier e contava com autores em diferentes estados como Acre, Amazônia, Distrito Federal, Goiás, Mato Grosso, Minas Gerais, Paraíba, Espírito Santo, Paraná, entre outros. PIROLA, 2008.

${ }^{47}$ MORAES; AROEIRA; CALDEIRA, 1981. 
com a escravidão", 48 enquanto que Bechepeche, Ordoñez e Sales sequer mencionam o tema. ${ }^{49}$

Outro ponto comum nas três obras é a inexistência de revoltas ou quaisquer outras formas de resistência escrava. Moraes é ainda mais enfático ao justificar a opção portuguesa pelo emprego da mão de obra africana em detrimento da indígena, devido a humildade e docilidade do africano.

Os portugueses, precisando de braços para a lavoura, quiseram aproveitar os indígenas. Estes porém, não se deixavam dominar facilmente. Eram rebeldes, indolentes, pouco produziam. Os portugueses, então, passaram a empregar os negros africanos. Eram mais fortes, resistentes [...] Além disso, eram bumildes, serviam sem protestar. ${ }^{50}$

Escrevendo sobre a história didatizada do período da ditadura militar, Telles identificou uma série de tentativas do regime da época em consolidar a representação de um país onde não havia racismo, com um passado harmonioso livre de revoltas ou outras formas de conflitos raciais. ${ }^{51}$ Este aspecto foi reiterado mesmo em manuais mais recentes como em Meu Estado - Espírito Santo, publicado em 1997, portanto em pleno regime democrático. Consolidando o discurso de que vivemos em uma democracia racial, as obras ressaltavam que "cada povo trouxe a sua contribuição para a formação de nossos costumes, nossa língua e nossa cultura". ${ }^{2}$ No entanto, ao apresentar as contribuições de índios, brancos e negros para formação étnica e cultural do Brasil, aquelas mesmas autoras confirmam uma suposta superioridade branca quando, por exemplo, no capítulo 6 - $A$ formação do nosso povo - após apresentarem a participação de índios, "brancos portugueses", negros africanos e imigrantes ${ }^{53}$ na constituição do povo capixaba, concluem a seção com uma atividade de fixação onde todas as questões reportam-se unicamente as contribuições dos imigrantes europeus.

De forma semelhante, Bechepeche, Ordoñez e Sales ao tratarem do folclore capixaba informam que a banda do congo é "formada por grupos de homens e mulheres que fazem um coro, cantando velhas e tradicionais toadas em que há referências à

\footnotetext{
${ }^{48}$ MORAES, 1964, p. 177.

49 BECHEPECHE; ORDOÑEZ; SALES, 1997.

${ }^{50}$ MORAES, 1964, p. 176-177, grifo nosso.

51 TELLES, Edward. Racismo à brasileira: uma nova perspectiva sociológica. Rio de Janeiro: Relume Dumará; Fundação Ford, 2003.

${ }^{52}$ MORAES; AROEIRA; CALDEIRA, 1981, p. 53.

${ }^{53}$ Notemos que as autoras distinguem as diferentes nacionalidades europeias, enquanto que homogeneíza os povos que habitavam o continente africano e americano.
} 
escravidão, à Guerra do Paraguai, aos santos de devoção popular, às sereias do mar, ao amor e à morte". 54

Não bastasse a referência esparsa a essa manifestação cultural enquanto herança negra, nas duas imagens (Ilustrações 1 e 2) que ilustram o congo, os sujeitos retratados não apresentam fenótipo negro.

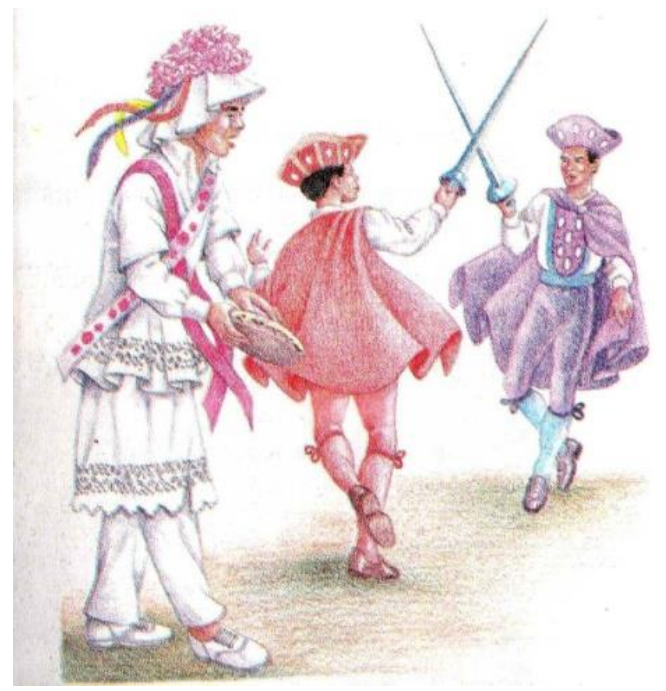

Ilustração 1

Fonte: BECHEPECHE; ORDONEZ; SALES, 1997, p. 42.

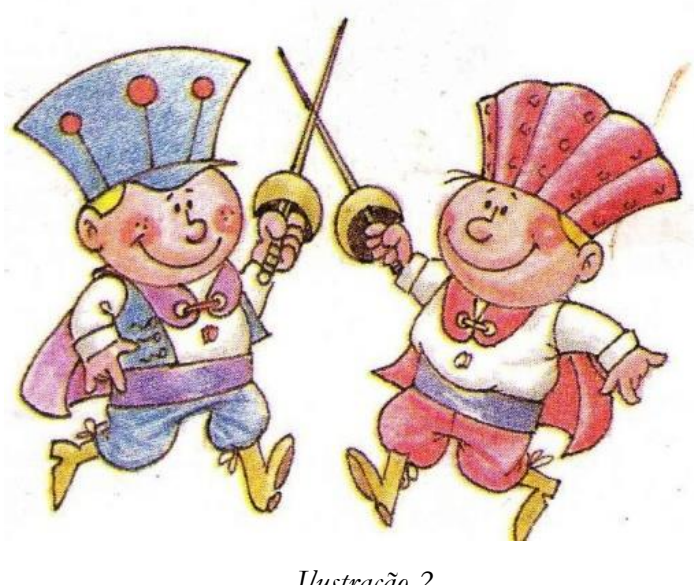

Fonte: BECHEPECHE; ORDOÑZZ; SALES, 1997, p. 04.

A hegemonia branca, que instituíra a escravidão e seu término e que agradecera a negros e índios sua contribuição para construção econômica e cultural do Brasil, é manifesta ainda quando os autores traduzem povoamento como sinônimo de presença europeia, afirmando que "o povoamento do Espírito Santo foi muito lento nos três primeiros séculos de nossa história". ${ }^{55}$ Essa situação é reafirmada em todas as obras analisadas neste artigo, seja quando tratam da colonização do Espírito Santo - "como as terras do Estado começaram a ser exploradas e povoadas?"56 - ou quando abordam o presente. É o que observamos no gráfico que ilustra o crescimento da população de Vitória, capital do Espírito Santo, impresso em Meu Estado- Espírito Santo (Ilustração 3). Na imagem, diversos sujeitos como idosos, crianças, operários e mulheres representam a população de Vitória totalmente branca e sem nenhum negro.

\footnotetext{
${ }^{54}$ BECHEPECHE; ORDOÑEZ; SALES, 1997, p. 42.

${ }^{55}$ BECHEPECHE; ORDOÑEZ; SALES, 1997, p. 26.

${ }^{56}$ MORAES; AROEIRA; CALDEIRA, 1981, p. 57.
} 


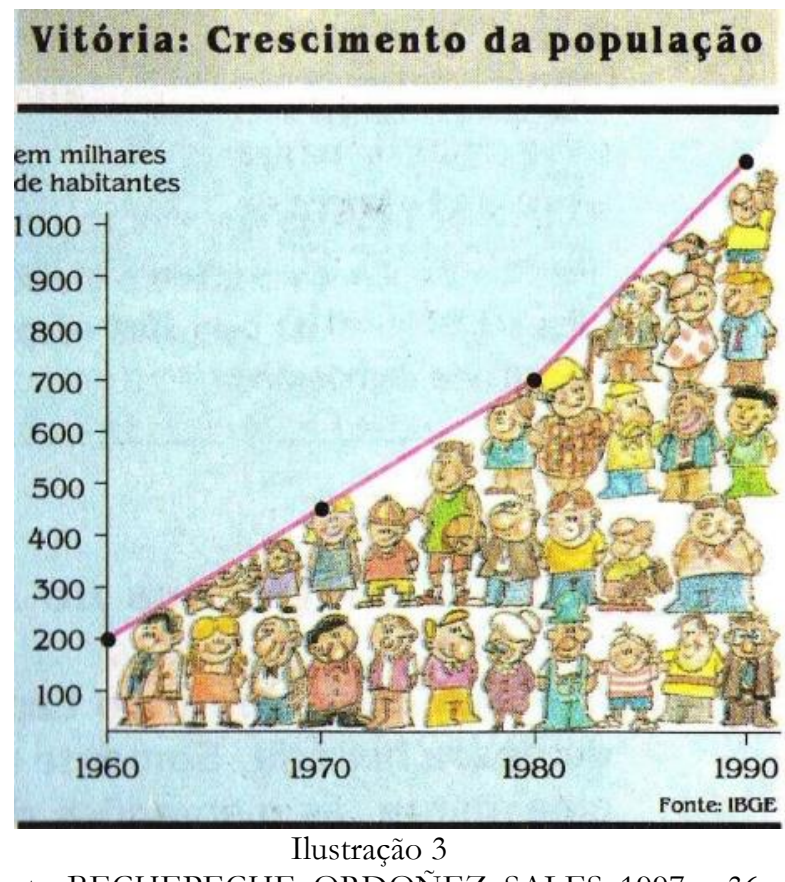

Fonte: BECHEPECHE; ORDOÑEZ; SALES, 1997, p.36.

Afinal, porque os livros, parte das coleções nacionais, produziram representações do negro distintas das encontradas nos livros produzidos no mesmo período por autores locais? Sugerimos que a resposta pode estar em um trecho de uma das obras didáticas de Luiz Guilherme Santos Neves, Léa Brígida Rocha de Alvarenga Rosa e Renato José Costa Pacheco, onde se apresentam aos seus leitores como "capixabas, ex-professores da Universidade Federal do Espírito Santo, membros do Instituto Histórico e Geográfico do Espírito Santo" (1997). ${ }^{57}$ Essas características, compartilhadas e reconhecidas por seus pares e que legitimaram a escrita didática de Neves, Rosa, Pacheco, Kill e Neida Lúcia não são encontradas entre os autores de Gente, terra verde, céu azul, Brasil: edição especial para o Espirito Santo e Meu Estado - Espírito Santo. Entre aqueles autores, com exceção de Morgana Bechepeche, ${ }^{58}$ nenhum deles é capixaba, tampouco produziram outras obras didáticas sobre o Espírito Santo, e além disso, não foram professores da UFES ou membros do IHGES. Portanto, ao não fazerem parte das gerações de intelectuais que escreveram a história capixaba, não compartilharam as mesmas representações que Léa Brígida Rosa, Luiz Guilherme Santos Neves ou Renato Pacheco, autores com os quais nos deteremos a seguir.

${ }^{57}$ NEVES, Luiz Guilherme Santos; ROSA, Léa Brígida Rocha de Alvarenga; PACHECO, Renato José Costa. Espírito Santo: Nossa história, nossa gente. Vitória: Grafer, 1997, p. 85.

${ }^{58}$ Observando outros livros da coleção, retratando a história e geografia de Santa Catarina e Rio Grande do Sul, percebemos que a estratégia adotada pela editora foi incentivar os paulistas Marlene Ordoñez e Geraldo Sales a reunirem-se a um autor local para produzirem esta obra. 


\section{OUTRAS PERSPECTIVAS}

Este livro não foi escrito para ser decorado pelos alunos. Os autores também professores - se sentirão melancolicamente decepcionados, se até simples frases desta obra forem decoradas por imposição dos docentes.

O objetivo do texto é de se prestar à utilização e leitura proveitosa, inteligente e crítica. Que se preste à discussão e à formulação de questões pelos alunos. Que leve os jovens a pensar, a concluir. ${ }^{59}$

Este trecho da Mensagem aos mestres não foi a única das "perspectivas didáticas diversas" ${ }^{60}$ encontradas na obra Espirito Santo, Minba Terra, Minba Gente (1986), primeiro livro didático de Léa Brígida Rosa, Luiz Guilherme Santos Neves e Renato Pacheco. Aqueles autores apoiados pela Secretaria Estadual de Educação adotaram uma escrita com forte caráter regionalista, o que para Pirola fazia parte de uma estratégia de rejeição às imposições do regime militar. ${ }^{61}$ Importante ressaltarmos que a construção deste livro deuse no governo de Gerson Camata, um dos governadores eleitos em 1982 em um partido de oposição ao governo militar, o PMDB, e que, no momento da publicação havia se licenciado para concorrer a uma vaga de senador. Naquele contexto, superar e rejeitar tudo que lembrasse o modelo educacional anterior era uma tendência comum adotada nos discursos e atitudes de alguns grupos políticos, dos intelectuais, das associações de professores e dos movimentos populares naquele momento de luta pela redemocratização do país.

Foi nesse cenário que o movimento negro, após as tentativas do regime militar de sufocá-lo na década de 1960 e da reestruturação e consolidação ocorrida no final da década seguinte, baseado nas pesquisas que denunciavam o caráter preconceituoso inscrito nos livros didáticos, exigiu uma revisão historiográfica que inserisse os negros e suas vitórias em uma narrativa oficial que até então os havia folclorizado e/ou menosprezado. Assim, em 1982, o Movimento Negro Unificado, que havia sido oficialmente criado em 1978, reivindicou em seu Programa de Ação a "luta pela introdução da História da África e do Negro no Brasil nos currículos escolares" ${ }^{62}$. No ano seguinte o deputado federal Abdias Nascimento, um dos mais importantes nomes do movimento negro brasileiro, apresentou

\footnotetext{
${ }^{59}$ NEVES, ROSA, PACHECO, 1986, p. 53

${ }^{60}$ PIROLA, 2008, p. 215.

${ }^{61}$ PIROLA, 2008, p. 215

${ }^{62}$ DOMINGUES, 2007, p. 104.
} 
o projeto de lei n. 1.332 que pretendia em seu artigo $8^{\circ}$ : "Eliminar a utilização de cartilhas ou livros escolares que apresentem o negro de forma preconceituosa ou estereotipada". ${ }^{63}$

Em 1987 durante os trabalhos da Assembleia Constituinte as entidades negras enviaram aos deputados uma agenda de reivindicações exigindo, entre outros, a "Reformulação dos currículos escolares visando à valorização do papel do negro na história do Brasil e à introdução de matérias como história da África e línguas africanas". ${ }^{64}$ Apesar da não aprovação do projeto e da não inclusão dessa proposta na Constituição de 1988, o movimento negro acumulou significativas vitórias no campo educacional a partir de então, como a aprovação de leis que readequavam os currículos escolares e inseriam a história da África e da cultura afro-brasileira em estados como a Bahia, 1989, e em cidades como Belo Horizonte, 1990, e Vitória, 1998. ${ }^{65}$ No nível federal apesar de as Leis de diretrizes e Base 4.024/1961 e 5692/1971 já condenarem o preconceito de raça, a grande virada ocorreria somente em 1995 quando, pressionado pelo Movimento Negro e pela Universidade, o MEC instituiu a Avaliação pedagógica passando a excluir livros didáticos inscritos no PNLD que veiculassem preconceito de origem, raça, sexo, cor e idade. ${ }^{66}$

Mesmo publicado em 1986, portanto, antes da aprovação de quaisquer das leis aqui mencionadas, Espirito Santo, Minha Terra, Minha Gente introduziu em seus textos e imagens uma representação do negro que a grande maioria dos livros didáticos do período ainda não havia incorporado. Se neste livro, e posteriormente em Nossa História, Nossa Gente, ${ }^{67}$ dos mesmos autores, persistiu a ênfase ao trabalho escravo e aos castigos, esses temas agora estavam acompanhados das diversas formas de resistência protagonizadas pelos escravizados em território capixaba, indo desde as fugas, as revoltas, como a de Queimado, e a formação de quilombos (termo destacado em fonte de formato negrito na obra de 1986).

${ }^{63}$ NASCIMENTO, Abdias. Projeto de Lei n. 1.332 de 1983. Diário do Congresso Nacional. Brasília: Câmara dos Deputados, 15 de junho de 1983, p. 5162-5165.

${ }^{64}$ HASENBALG, Carlos A. Entre o mito e os fatos: racismo e relações raciais no Brasil, Dados - Revista de Ciências Sociais, Rio de Janeiro, v. 38, n. 2, p. 360, 1995, apud PAULA, Cláudia Regina ; LOPES, Carla (org.) . O protagonismo negro: o Movimento Negro na luta por uma educação antirracista, Acervo, Rio de Janeiro, v. 22, p. 111, 2009.

${ }^{65}$ PAULA; LOPES, 2009.

${ }^{66}$ BOULOS JÚNIOR, Alfredo. Imagens da África, dos africanos e seus descendentes em coleções de didáticos de História aprovadas no PNLD 2004. 204 f. Tese (Doutorado em Educação) - Pontifícia Universidade Católica de São Paulo, São Paulo, 2008.

${ }^{67}$ NEVES; ROSA; PACHECO, 1997. 


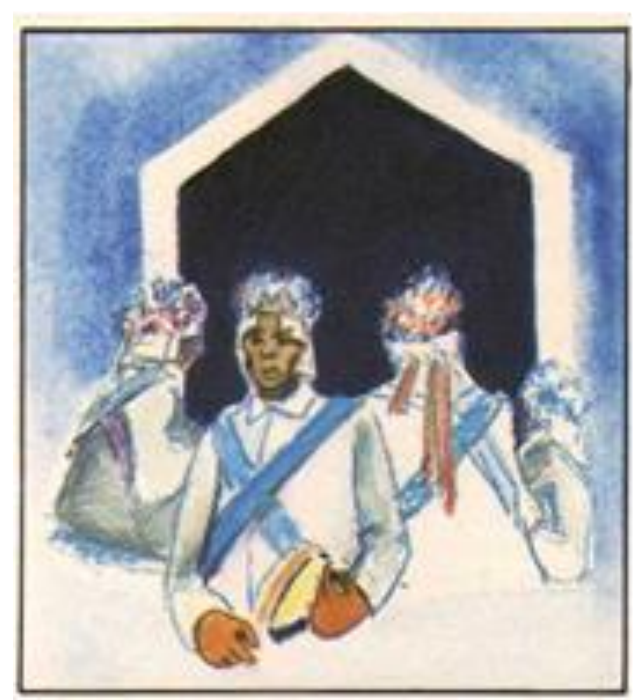

Ilustração 4

Fonte: NEVES, ROSA; PACHECO, 1986, p. 13.

Mesmo quando reiteram aspectos das representações anteriormente consolidadas como a contribuição cultural, Neves, Rosa e Pacheco ressaltam o papel do negro, como verificamos nos textos e imagens que ilustram o folclore e as tradições capixabas (Ilustração 4). No caso específico do livro de 1986, todas as imagens retratam manifestações culturais negras.

Outra inovação dessa obra é o fato dos negros não estarem apenas relacionados a eventos do passado.

Os negros vêm tendo uma participação muito destacada na vida social, econômica e cultural do Brasil, tendo marcado, também, a formação da gente capixaba. Estes traços marcantes são notados, por exemplo, na musicalidade do povo, no artesanato e culinária, nas letras e nas artes, no campo da religiosidade, na existência de elevado número de descendentes e mestiços que formam a nossa população. ${ }^{68}$

Em Nossa História, Nossa Gente (1997), Neves, Rosa e Pacheco consolidaram essa representação introduzida na obra anterior. Se os críticos apontariam que a obra remetia apenas ao excêntrico, o folclórico, os agora afro-brasileiros ${ }^{69}$ destacam-se na música e nas festas, mas também:

Sua presença atuante pode ser registrada no magistério, no serviço público, civil e militar, nos esportes, nas profissões liberais, nas chefias

\footnotetext{
${ }^{68}$ NEVES, ROSA, PACHECO, 1986, p. 27.

${ }^{69}$ A utilização desse termo pela primeira vez em uma obra de história do Espírito Santo simboliza essa nova interpretação e a força do movimento negro
} 
do Poder Executivo e Judiciário, na Assembleia legislativa e nas Câmaras Municipais. ${ }^{70}$

Desta forma, as representações em que o negro auxiliava o projeto colonizador, o negro coisificado, passam a conviver com o afro-brasileiro apresentado enquanto protagonista. Nesse sentido, "a lei [Áurea] foi o resultado de uma conquista demorada em que os negros, com suas revoltas, suas fugas e quilombos, tiveram papel decisivo". ${ }^{71} \mathrm{O}$ africano, antes singular, é substituído pelo povo multiétnico (Ilustração 5), que nunca aceitou a escravidão.

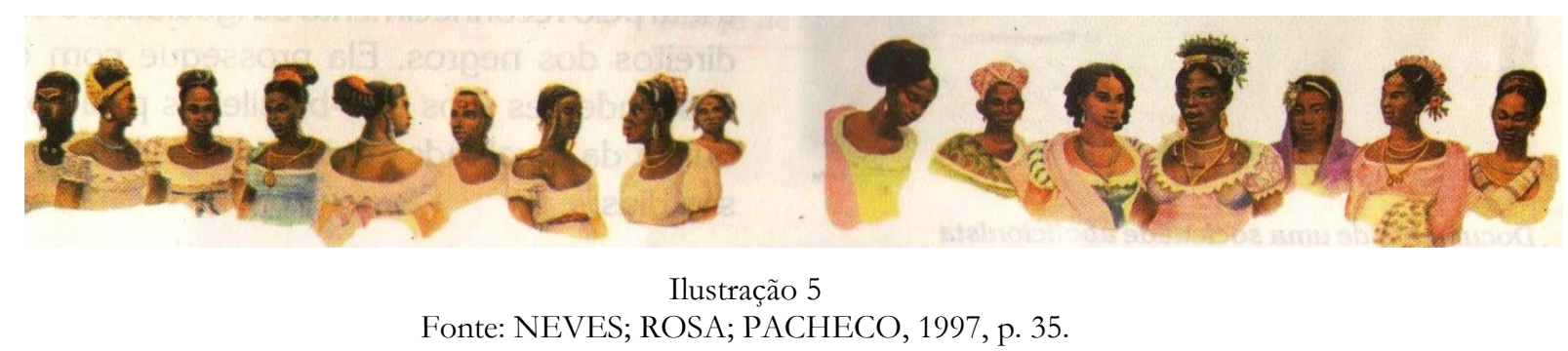

O fato é ainda mais emblemático se considerarmos que o livro Espirito Santo, Minha Terra, Minha Gente foi publicado em 1986, portanto, antes dos três episódios que Boulos Junior aponta como cruciais na luta do movimento negro: a Constituição de 1988, as comemorações do Centenário da Abolição em 1988, e a III Conferência Mundial contra o Racismo, Discriminação Racial, Xenofobia e Intolerância em 2001. ${ }^{72}$ Além disso, a narrativa inscrita em Espirito Santo, Minha Terra, Minha Gente destoa dos livros escolares analisados por pesquisas publicadas nos anos 1980 e 1990 que denunciaram "um quadro de depreciação sistemática de personagens negros, associada a uma valorização sistemática de personagens brancos". ${ }^{73}$ Esses dados nos permitem concluir que, apesar de perpetuar uma narrativa eurocêntrica a historiografia didática capixaba produzida por autores locais incorporou as reivindicações do movimento negro e a renovação historiográfica, no que tange a questão negra, de forma muito mais intensa, do que as obras de história do Brasil, ou mesmo as obras de história do Espírito Santo escrita por autores de outros estados.

\section{CONSIDERAÇÕES FINAIS}

${ }^{70}$ NEVES; ROSA; PACHECO, 1997, p. 37.
${ }^{71}$ NEVES; ROSA; PACHECO, 1997, p. 36.
${ }^{72}$ BOULOS JUNIOR, 2008.
${ }^{73}$ ROSEMBERG; BAZILLI; SILVA, 2003, p. 136. 
Produzimos esta pesquisa objetivando verificarmos os tipos de representações do negro foram construídas nos livros didáticos de história publicados no período da ditadura militar e nos primeiros, aproximadamente, quinze anos após a redemocratização do país. Em nossa hipótese inicial apostávamos na apuração de dois modelos distintos, determinados, sobretudo, por aqueles dois contextos políticos. No entanto, à medida que avançamos na análise das obras selecionadas, começamos a delinear outra divisão que não parecia tomar conhecimento do regime político que vigorava no momento em que foram publicadas. De um lado, estavam os livros didáticos escritos por autores capixabas, professores da UFES e membros do IHGES - Miguel Kill, Neida Lúcia de Moraes, Léa Brígida Rosa, Luiz Guilherme Santos Neves e Renato Pacheco -, do outro, os livros didáticos produzidos por autores de outros estados e parte de coleções nacionais.

Neida Lúcia de Moraes inaugurou em O Espírito Santo é Assim (1971) uma representação do Espírito Santo enquanto um Estado que, a despeito de um passado marcado pelo atraso e isolamento, caminhava a passos largos em direção ao desenvolvimento, representação que influenciou a produção didática capixaba nas próximas quatro décadas. $\mathrm{Na}$ questão específica dos africanos e seus descendentes, Moraes iniciou também uma escrita que acabaria ditando o modelo de narrativa sobre esses indivíduos. Em tom panfletário, a autora introduzia na história escolar capixaba a Insurreição de Queimado, apontada e reconhecida pela historiografia capixaba como a maior revolta negra da história do Espírito Santo. A partir de então, mesmo que não houvesse uma legislação que assim os exigisse, os autores locais foram recondicionando e superpondo representações do negro nos livros escolares capixabas que iam desde o clássico auxiliar ao projeto colonizador português até o inovador rebelde.

Na década de 1980, o livro Espírito Santo, Minha terra, minha gente (1986), de Rosa, Neves e Pacheco; mesmo mantendo uma perspectiva eurocêntrica; consolidou e aprofundou a representação construída por Neida Lúcia Moraes e Miguel Kill. Em Espírito Santo, Minha terra, minha gente os africanos e seus descendentes, além de contestadores, possuíam uma história anterior a chegada ao Brasil e posterior à abolição, inclusive no presente, fato inusitado nos livros publicados no mesmo período. ${ }^{74}$

${ }^{74}$ NEVES; PACHECO; ROSA, 1986. 
Por outro lado, os livros escritos por autores de outros estados, apresentavam uma narrativa distinta daquela apresentada pelos autores locais. Naquelas obras, inclusive em Coleção Meu Estado - Espírito Santo, publicada em 1997, o negro era retratado apenas em eventos restritos ao passado distante e exercendo papéis subalternos, enquanto que as revoltas ou qualquer outra forma de resistência negra, sequer eram abordadas. ${ }^{75}$

Para Juçara Luzia Leite, as permanências marcam a historiografia do Espírito Santo escrita por diferentes gerações de intelectuais que inseriram novas interpretações sem negar as anteriores, havendo um condensamento e sobreposição de representações, sendo as permanências, e não as rupturas, que ditaram o tom dessa escrita. ${ }^{76}$ No caso específico do negro, essa característica reiterou e perpetuou uma representação inovadora, especialmente se comparada com o que aconteceu, no mesmo período, a nível nacional.

${ }^{75}$ MORAES, 1964.

${ }^{76}$ LEITE, 2007. 